\title{
SUBAORTIC STENOSIS
}

\author{
BY \\ VIKING OLOV BJÖRK,* BENGT JONSSON, AND BJÖRN NORDENSTRÖM \\ From the Chest Unit, Karolinska Sjukhuset, Stockholm, Sweden
}

(RECEIVED FOR PUBLICATION MAY 20, 1958)

In subaortic stenosis there is a localized narrowing of the outflow tract of the left ventricle. This ridge, or stenosing fibrous collar composed of elastic and collagenous tissue, involves the ventricular septum as well as the ventricular surface of the anterior leaflet of the mitral valve. Either a thick ring of muscular and fibrous tissue is found immediately below the aortic valve or a thin membraneous diaphragm with a central opening less than 1 to $2 \mathrm{~cm}$. below the aortic valves is encountered (Gould, 1953). The subaortic stenosis due to a thin diaphragm may easily be corrected by finger fracture through the aortic wall under hypothermia. The aim of this paper is to present a case of subaortic stenosis correctly diagnosed pre-operatively by selective left ventricular angiocardiography with contrast injection through a needle placed percutaneously into the left ventricle. The diagnosis was verified at operation performed under hypothermia.

\section{CASE REPORT}

K. S. (440512) was a boy, aged 13. Heart disease was diagnosed at the age of 6 . Since then he has had attacks of angina pectoris on exertion but never attacks of syncope. He was slightly disabled. The development was normal. The physical findings were typical for a severe aortic stenosis, namely, an increased cardiac impulse, a long systolic murmur, grade 5 , over the aortic area transmitted to the neck. On a phonocardiogram the murmur was diamond shaped with the maximal intensity late in systole. Only the pulmonary component of the second sound could be identified. The blood pressure was $90 / 70 \mathrm{~mm}$. Hg. The E.C.G. showed signs of marked left ventricular hypertrophy. The radiological examination showed no enlargement of the heart, but a change of the configuration as in left ventricular hypertrophy. The electrokymogram was typical of an aortic stenosis. The left ventricular pressure was recorded after direct puncture of the ventricle. It was found to be $185 \mathrm{~mm}$. $\mathrm{Hg}$ systolic and 15 end-diastolic. The systolic pressure in the left arm, measured with a cuff simultaneously with the puncture, was $130 \mathrm{~mm}$. Hg. A selective angiocardiograph of the left ventricle was then performed with contrast injection direct through the puncture needle (Fig. 1) and showed a narrow portion

* Now thoracic surgeon in chief, Akademiska Sjukhusot (University Hospital). Upsala, Sweden.
$1 \mathrm{~cm}$. below the aortic cusps in the left ventricle and also some fusion of the aortic cusps. They never opened completely during ventricular systole but were thin and flexible. The left ventricular wall was found to be thick and hypertrophied and over $1 \frac{1}{2} \mathrm{~cm}$. in thickness. No contrast regurgitation to the left atrium was observed. The pre-operative diagnosis was therefore subvalvular and valvular stenosis.

The operation was performed using hypothermia, the patient first being immersed in ice water. A bilateral subcostal incision on the left side under the fourth and on the right side under the third rib was performed with transection of the sternum. The innominate artery, the left carotid artery, the superior vena cava, the inferior vena cava, the left pulmonary veins, and the right pulmonary veins were dissected free and surrounded by a tape for occlusion. When the oesophageal temperature was $29.1^{\circ}$ Celsius and the $p \mathrm{H} 7.54$ an inflow-occlusion was made. First the inferior and superior venae cavae were occluded. After 30 seconds the left carotid artery and the innominate artery as well as the pulmonary veins from both sides were occluded and an occlusion clamp placed over the root of the aorta and prostigmine injected into the aorta (Swan, Wilkinson, and Blount, 1958). The base of the aorta had earlier been dissected and a Supersatinsky clamp placed longitudinally over the ascending aorta as close to the coronary artery as possible. The excluded portion of aorta had then been opened. Immediately after injection of the prostigmine, the Supersatinsky clamp was removed and the aortic cusps inspected; the commissure between the right and posterior aortic cusps was normal as well as the commissure between the left and posterior cusps. The commissure between the right and left aortic cusp was, however, partly fused and it was possible to open this fusion with scissors for about $4 \mathrm{~mm}$. It was obvious that the fusion between the aortic cusps could not explain the patient's symptoms and the pressure gradient. The left index finger was therefore introduced through the aortic orifice, and between 1 and $2 \mathrm{~cm}$. below the aortic valves a thin fibrotic ring was palpated open for the tip of the finger. The opening was judged to be 7-9 $\mathrm{mm}$. in diameter and felt by palpation exactly like a tight mitral stenosis. It was easy to fracture this membraneous diaphragm and afterwards to introduce the index finger far down into the left ventricle. It could be felt that the diaphragm was split all the way to the ventricular wall. The occlusion from the left pulmonary vein was relieved. When the left ventricle 


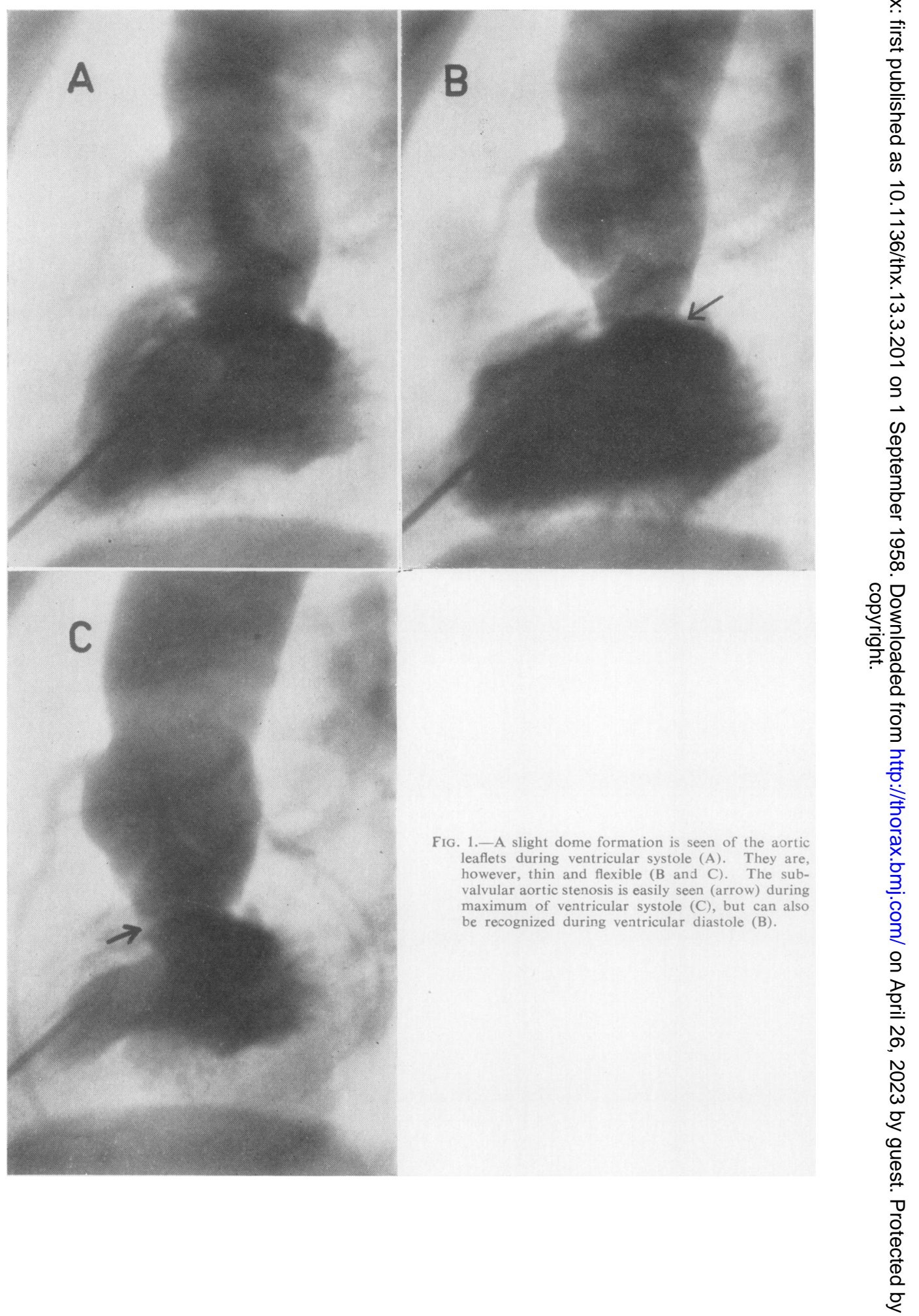


and the aorta had filled with blood from the lung, three minutes of occlusion had passed and a further three minutes were used to place a row of isolated mat tress-sutures in the proximal part of the incision in the aorta. After six minutes of occlusion the Supersatinsky clamp was placed over the incision in the aorta and the occlusion clamp placed transversally over the aorta was immediately removed and the superior vena cava was opened. After a further $\mathbf{2 0}$ seconds the occlusion tapes from the left carotid artery and the innominate artery were opened and finally the tape from the inferior vena cava. The heart immediately took over the circulation and maintained a good systolic blood pressure, the incision in the aorta was closed with 5:0 (mattressinterrupted) sutures and one row over and over 5:0 sutures on an atraumatic needle. There was an insignificant leakage in the suture line. However, to prevent the possibility of an aneurysm forming in the dilated aorta a thin collar of "ivalon" sponge, $5 \mathrm{~cm}$. wide, was placed around the ascending aorta, so covering the whole incision. Primary suture was performed with two tubes for drainage in each chest cavity. The patient made an uneventful recovery.

\section{Discussion}

This is a case pre-operatively correctly diagnosed as a subaortic stenosis by means of selective left ventricular angiocardiography. By left heart catheterization a pressure gradient of $55 \mathrm{~mm}$. $\mathrm{Hg}$ over the aortic valve could be established. However, to make a correct pre-operative diagnosis by pressure measurements alone, i.e., the withdrawal pressure curve over the aortic orifice, seems impossible in cases of subaortic stenosis as this membrane is placed so close to the aortic leaflets so that there is actually no real third ventricular chamber. The aortic leaflets are usually described as normal in cases of subaortic stenosis and its orifice of normal size, but a few cases have been reported where there are valvular malformations as well. In our case the valves were thin and flexible except in one commissure where there was a slight fusion, which, probably, was insignificant from a haemodynamic point of view.

\section{SUMMARY}

A case is described in which pre-operatively a subaortic stenosis was correctly diagnosed by selective left ventricular angiocardiography. The diagnosis was confirmed at operation performed under hypothermia.

\section{REFERENCES}

Gould, S. E. (1953). Pathology of the Heart. Charles C. Thomas, Springfield, Illinois.

Swan, H., Wilkinson, R. H., and Blount, S. G. (1958). J. thorac. Surg., 35, 139. 